\title{
Mechanic and Eneroroy
}

Morro do Cruzeiro

UFOP Campus

evaluation of indoors

climatic conditions

\author{
Marcela A. Faria \\ Pós-graduanda do Programa de Pós-Graduação \\ em Engenharia Civil - PROPEC \\ Universidade Federal de Ouro Preto - UFOP \\ Escola de Minas \\ Departamento de Engenharia Civil \\ Ouro Preto - Minas Gerais - Brasil \\ maafaria@hotmail.com \\ Henor Artur Souza \\ Professor Titular \\ Universidade Federal de Ouro Preto - UFOP \\ Escola de Minas \\ Departamento de Engenharia de Controle e \\ Automação e Técnicas Fundamentais \\ Ouro Preto - Minas Gerais - Brasil \\ henorster@gmail.com
}

\section{Introduction}

The building environment, its process of production and usage are not just simple concrete expressions, since they ought to express and interpret the reaction of its individual users in a variety of ways in accordance with a human's basic needs, attitudes, cultural values, images and society ideals.

One of the functions of architecture is to provide thermal conditions compatible to the human thermal comfort inside buildings, regardless of the external climatic conditions. Within this context, the correct choice of materials composing the finalization of building must follow specific criteria while taking into consideration not only the cost-benefit relationship, but also the local climate because the choice of an inadequate material may cause an increase in electrical energy consumption to the

\begin{abstract}
The comfort conditions of a given environment can directly influence the performance of the activities performed therein. When considering the school space in relationship with the user, the environment is even more important, since it may reflect fully on the learning process. This article evaluates the thermal comfort perceptions of classroom users of the Federal University of Ouro Preto, specifically the School of Mining, the Institute of Physical and Biological Sciences and the Building Block of Classrooms. The research is conducted through questionnaires and measurements of environmental variables in loco simultaneously in the three areas throughout the months of June, July and September 2011. The results were statistically analyzed using the calculation of the standard deviation from the mean operative temperature and humidity to give comfort zone. Approximately $75 \%$ of the users were satisfied with the thermal environment.
\end{abstract}

keywords: thermal comfort, school, individual users.

environments conditioning during highly elevated or lower than average temperatures.

A sustainably designed building with features that provide a convenient environmental thermal response does not imply a mandatory increase in construction costs, but rather, it must result in utilization and maintenance cost reductions, as well as provide more pleasant internal environmental conditions for its occupants. The more satisfactory the climatic conditions are in the environment, the more optimized will be the task performed in this location.

Studies like the one conducted by Wong and Khoo (2002), reinforce the fact that the thermal condition inside the classrooms in school buildings ought to be carefully considered prior to construction, especially because of the high density of occupation and also because of the negative influences that an unsatisfactory thermal environment has on the learning and performance of its users. Other research has been undertaken about the environmental comfort of school architecture, thus underscoring the need to determine improvements in the classrooms so teaching and learning can be improved with better quality (PIZARRO, 2005; CORGNATI; FILIPPI; VIAZZO, 2007).

The objective of this study is to evaluate the thermal environment of classrooms in Campus Morro do Cruzeiro, Federal University of Ouro Preto (UFOP), specifically the School of Mining, the Institute of Physical and Biological Sciences and the Building Block of Classrooms, thus investigating the perception of users (Figure 1). 

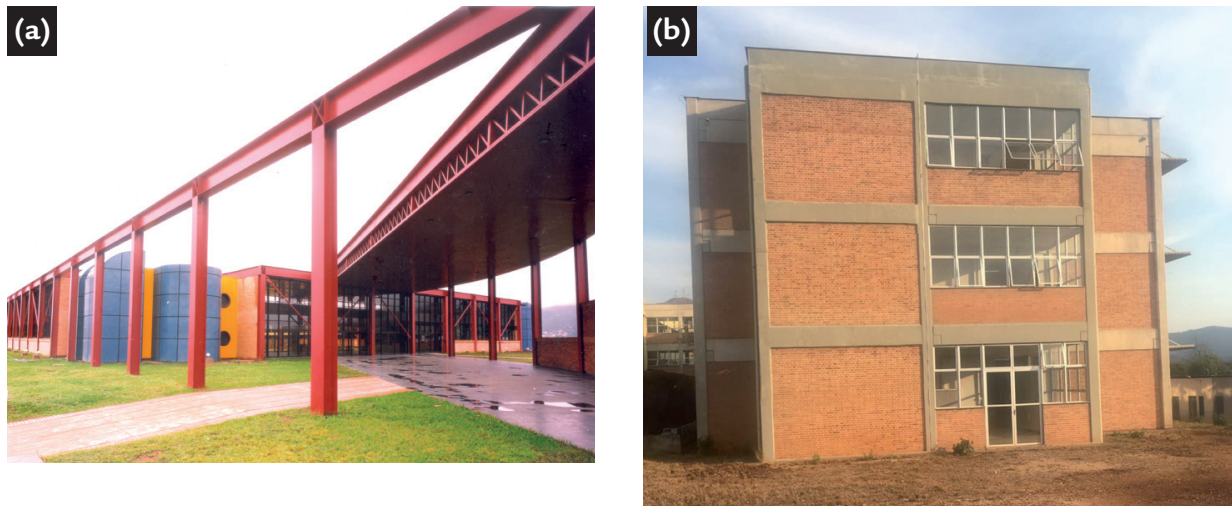

(c)

\section{Materials and methods}

The research was conducted in the university population that attends three buildings UFOP, Campus Morro do Cruzeiro, Ouro Preto - MG: School of Mining, Institute of Physical and Biological Sciences and Building Block of Classrooms.

The method of work was to obtain at the same time, the value of the environmental variables that influence thermal comfort of users of the classrooms in these buildings, by measuring in site, as well as the perception that these individuals have of them through questionnaires given to these users.

For field testing, the following procedures were adopted: (a) mounting the sensors and data acquisition system in the classroom and the measurement of temperature, air velocity and humidity over a period of 1 hour, in steps of 5 minutes; (b) explain to students the research objectives and distribution of questionnaires that they would fill out according to their sensations at that moment; (c) collecting the questionnaires and data collection continued until the end of the given period, in this case 1 hour.
Figure 1

Buildings Campus Morro do Cruzeiro - UFOP
(a) School of Mining (Arquivo :REM)
(b) Institute of Physical and Biological Sciences
(c) Building Block of Classrooms

Fonte: FARIA, 2012

$$
\begin{gathered}
\mathrm{T}_{\mathrm{r}}=\left[\left(\mathrm{T}_{\mathrm{G}}+273\right)^{2}+0,4 \cdot 10^{8} \cdot\left(\mathrm{T}_{\mathrm{G}}-\mathrm{T}_{\mathrm{ar}}\right)^{1 / 4} \cdot\left(\mathrm{T}_{\mathrm{G}}-\mathrm{T}_{\mathrm{ar}}\right)\right]^{1 / 4}-273 \\
\mathrm{~T}_{0}=\frac{\mathrm{h}_{\mathrm{c}} \cdot \mathrm{T}_{\mathrm{ar}}+\mathrm{h}_{\mathrm{r}} \cdot \mathrm{T}_{\mathrm{r}}}{\mathrm{h}_{\mathrm{c}}+\mathrm{h}_{\mathrm{r}}}
\end{gathered}
$$

For measuring in site internal temperature and internal moisture were used resistive and capacity sensors, respectively, anemometer and global thermometer connected to a data acquisition system (ALMEMO, 2003). The sensors were fixed on a metal support measured in three different positions, as suggested by ISO 7726 (ISO, 1996) standard.

From the measured variables in the classrooms, the radiant temperature (equation 1) and operative temperature (equation 2) was calculated, considering the natural convection,

here $T_{r}$ is the radiant temperature $\left({ }^{\circ} \mathrm{C}\right) \mathrm{T}_{\mathrm{C}}$ is the globe temperature $\left({ }^{\circ} \mathrm{C}\right)$ $\mathrm{T}_{\mathrm{ar}}$ is the air temperature $\left({ }^{\circ} \mathrm{C}\right)$ and $\mathrm{T}_{0}$ is the operative temperature $\left({ }^{\circ} \mathrm{C}\right), h_{c}{ }_{c}$ is the coefficient of heat transfer by convection $\left(\mathrm{W} / \mathrm{m}^{2} \mathrm{~K}\right)$, and that was considered equal to $3.1 \mathrm{~W} / \mathrm{m}^{2} \mathrm{~K}$ (person sitting at an air speed between 0 and $0.2 \mathrm{~m} / \mathrm{s}$ ), and $h_{r}$ is the coefficient of heat exchange by radiation $\left(\mathrm{W} / \mathrm{m}^{2} . \mathrm{K}\right)$, adopted the typical value of $\mathrm{h}_{\mathrm{r}}=4.7 \mathrm{~W} / \mathrm{m}^{2} . \mathrm{K}$ (ASHRAE 55, 2010).

From the completion of the questionnaire by the students, were counted the subjective preferences of users and then correlations and statistical analysis of these results were made.

To analyze the correlations of data obtained through the questionnaire it was divided into thermal sensation on a 7-point scale (ASHRAE, 2010), which represents very cold (MF or -3 ), cold (F or -2 ), slightly cold (LF or -1 ), thermoneutral (C or 0 ), slightly warm (or LQ +1 ), hot (or
$\mathrm{Q}+2)$ and very hot (MQ or +3$)$ while representing the feeling that students were having at that time.

The sample was 320 individuals have been held in total 12 field tests with questionnaires and measurements of temperature and humidity. These essays were performed at 2 in the Institute of Physical and Biological Sciences, 3 in the Building Block of Classrooms and 7 in the School of Mining, on 08, 09, 14 and 16 June, 13 in July and 19, 20 and 22 September 2011. 


\section{Results}

\subsection{Correlations between the psychophysiological variables}

In the figure 2 (graphics $a, b, c)$ presented are the judgments of users within the classrooms assessed against this scale of subjective preference of comfort. We note that in relation to the

Figure 2

Subjective judgments about thermal comfort. analyzed environments there is neutrality to a percentage above $45 \%$ of the occupants in the environment, considering the three buildings analyzed. The trials, taking into account each building

\section{(a)}

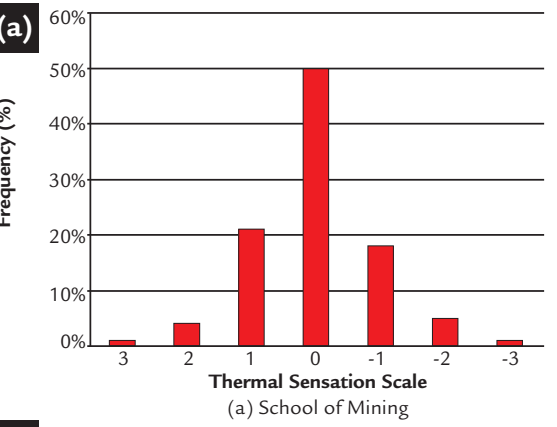

(c)

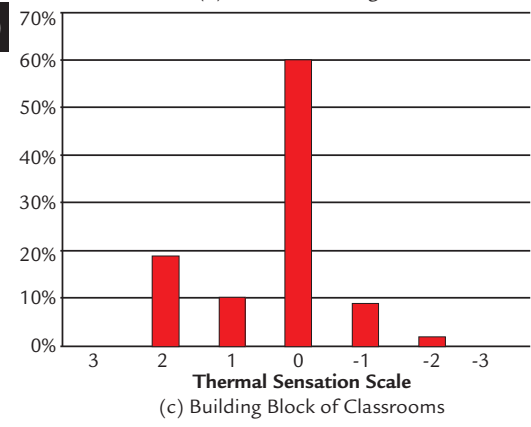

\subsection{Crossing between environmental variables and psychophysiological}

These variables were measured in subjective scales, according to the students of each separate field who filled the questionnaire and were analyzed

Figure 3

(a) Crossing the air temperature with the thermal sensation; (b) Crossing the relative humidity with the thermal sensation; (c) Crossing the globe temperature with the thermal sensation; (d) Crossing the operative temperature with the thermal sensation.

separately are also similar, with the majority voting in neutral $(0)$, then slightly cold and slightly warm $(+1$ and -1$)$ and minority in hot or cold $(-2$ to +2$)$ and few in very cold or very hot $(-3$ to +3$)$.

(b)

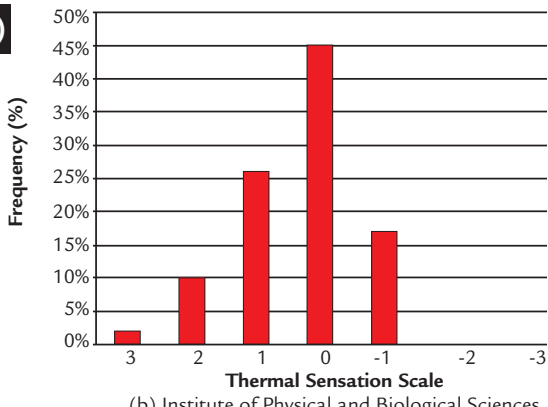

(b) Institute of Physical and Biological Sciences

sensation variable measuring the environmental variables: temperature and relative humidity of the indoor air, globe temperature and operative temperature. ronment. In Figure 2, graphcs a), b), c) and d) presents the crossing's thermal

(b)

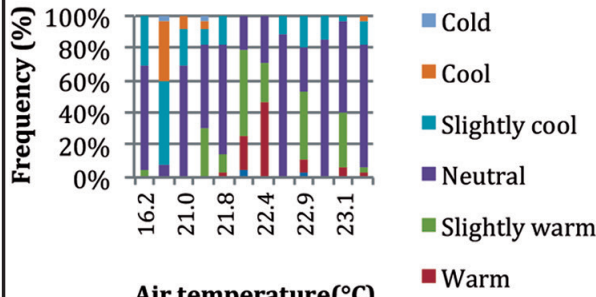

(c)

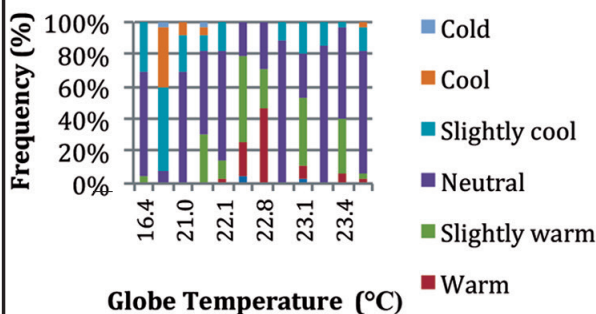

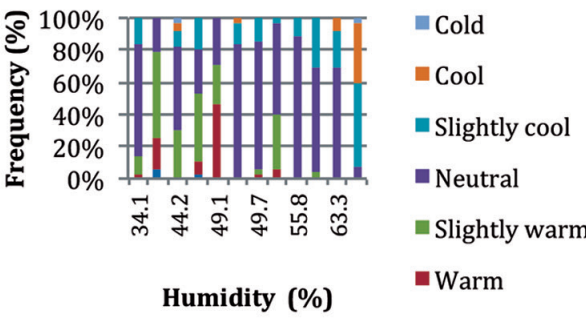

(d)

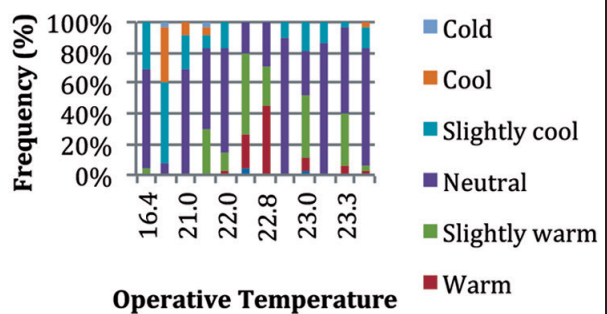


From the graphical analysis it follows the percentage of votes in the category $\mathrm{C}$ of thermal sensation scale was significantly correlated with all environmental variables except moisture, which was moderately positive. Grades Hot, Warm and Slightly Warm showed a moderate negative correlation with $T_{\text {ar }}$

(air temperature), $\mathrm{T}_{\mathrm{G}}$ (globe temperature), $\bar{T}_{r}$ (mean radiant temperature) and $\mathrm{T}_{\mathrm{o}}$ (operative temperature) variables. The grades Slightly Cool, Cold and Cool showed a weak to moderate correlation with these variables and negative. The degrees Cool and Slightly Cool showed positive, moderate and weak correlations, respectively, with variable moisture, while the degree Hot, Slightly Warm and Warm showed a moderate negative correlation. In the Figure 4, graphcs a), b) e c) presents the intersection of variable satisfaction with the environment in relation to temperature and relative humidity measured in the site.

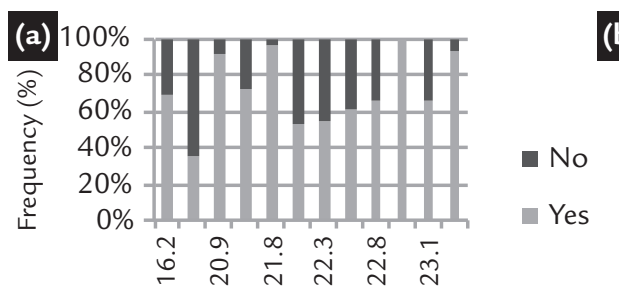

Air Temperature $\left({ }^{\circ} \mathrm{C}\right)$

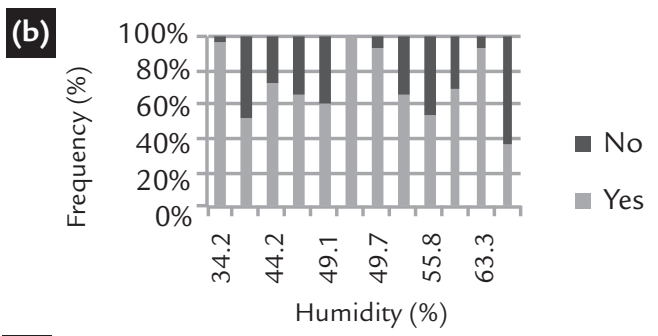

(c)

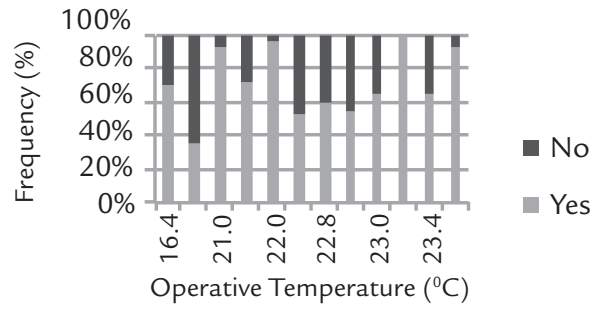

Overall, the level of satisfaction remains good, with minor fluctuations, throughout most of the observed temperature range, falling considerably in temperature around $20^{\circ} \mathrm{C}$ for both $\mathrm{T}_{\text {ar }}$ and for $T_{0}$. The degree of satisfaction with the humidity of the atmosphere

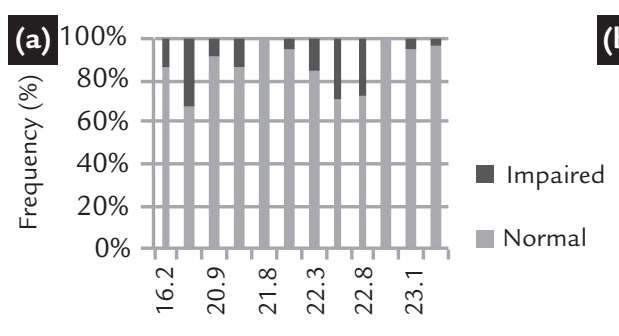

Air Temperature $\left({ }^{\circ} \mathrm{C}\right)$

From these analyzes, it is observed that in general the level of acceptance of environment varies greatly. It is noted that it falls either from high temperatures but also at lower temperatures. Between these extremes, there is an oscillation, but the environment is still acceptable for most users.

3.3 Definition of the limits of thermal comfort had a major shift. The results show that the level of satisfaction is not an exclusive function of environmental conditions. Fluctuations may have occurred because of the use of adaptive mechanisms such as the type of clothing used by individuals, thus resulting

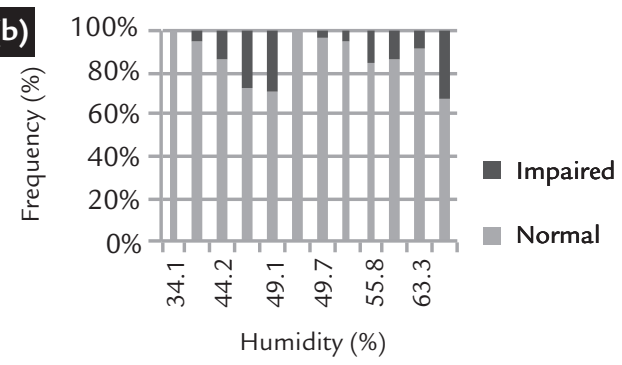

\section{(c)}

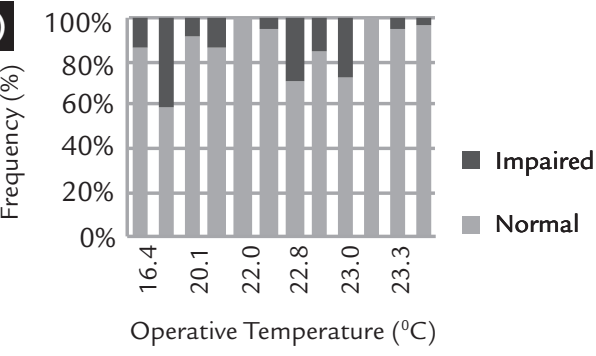

After formatting the data collected in the field, we proceeded to determine the limits of thermal comfort for the population under study, from the proportions of votes collected for each degree of windchill factor.

The statistical analysis used to determine the results related to the comfort zone, from the data collected from users of thermal sensation, took into account
Figure 4

Crossover (a) air temperature, (b) relative humidity and (c) the operative temperature, satisfaction with the environment.

in different levels of satisfaction. In Figure 5 graphcs, a), b) e c) shows the crossing of judgments of the capacity to study the environment (considered by students as normal or impaired) with temperature and relative humidity and operating temperature.
Figure 5

Crossover (a) air temperature, (b) relative humidity and (c) the operative temperature, with the ability to study the environment.

the calculation of the mean operative temperature and relative humidity, and from these the standard deviation $(\delta)$ for determination of confidence intervals of temperature and humidity.

Theoretically, it is estimated that for normally distributed data, the range of $\pm 1 \delta$ includes $68 \%$ of responses and $\pm 2 \delta$ includes $95 \%$ of the responses (RUIZ-TORRES et al., 2009). There- 
fore, its been used preferably for the range of operative temperature and the relative humidity range between $\pm 2 \delta$, as the confidence interval that you may want to adopt.

The steps for obtaining a range of comfort in relation to operative temperature and relative humidity are as follows:

i) Obtains the operative temperature $\left(T_{0}\right)$ using equation (2), mean radiant temperature $\left(\bar{T}_{r}\right)$ obtained by equation (1):

ii) To obtain the range of operative temperature and relative humidity (intervals), by using the statistic method calculating the standard deviation from the average, followed these steps:

a) All answers resulting from the thermal sensation scale are classified with the respective values of temperature and

Figure 6

Thermal sensation $x$ relative humidity (UR) and the operative temperature $\left(T_{0}\right)$

The charts axis represents the average responses to the thermal sensation of users depending on the operative temperature and relative humidity respectively. The first track from the center line (average) on both sides represents the standard deviation $\pm 1 \delta$ for each group of thermal sensation as a function of operative temperature and relative humidity respectively. The second track

\section{Graph 9}

Psychrometric diagram with the parameters of certain thermal comfort. relative humidity obtained.

b) Determined the average of each group of thermal sensation as a function of the value of operative temperature and relative humidity.

c) Compute the standard deviation, $\pm 1 \delta$ and $\pm 2 \delta$, for each group of thermal sensation as a function of operating temperature and relative humidity.

d) Take as a benchmark for both the operative temperature and for relative humidity, the value of $\pm 2 \delta$ (referring to $95 \%$ probability of occurrence). These values of operative temperature and relative humidity are obtained from the intersection of the line for $-2 \delta$ and $+2 \delta$, with the line of thermal sensation of thermal neutrality $(0)$, read this value in the " $\mathrm{x}$ " axis.

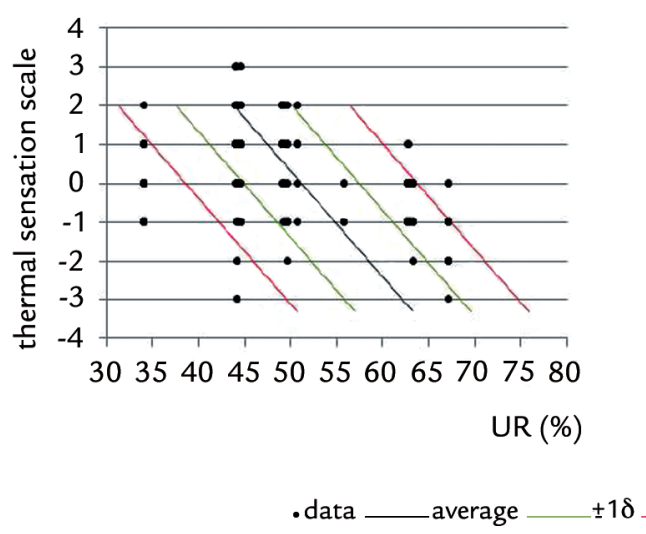

from the center line (average) on both sides represents the standard deviation $2 \delta$, for each group of thermal sensation as a function of operative temperature and relative humidity, respectively.

The comfort zone was defined based on the intervals $\pm 2 \delta$ obtained for the entire study period (representing $95 \%$ probability of occurrence). The values of operative temperature and

Atmospheric pressure $=87,9402 \mathrm{kPa}$

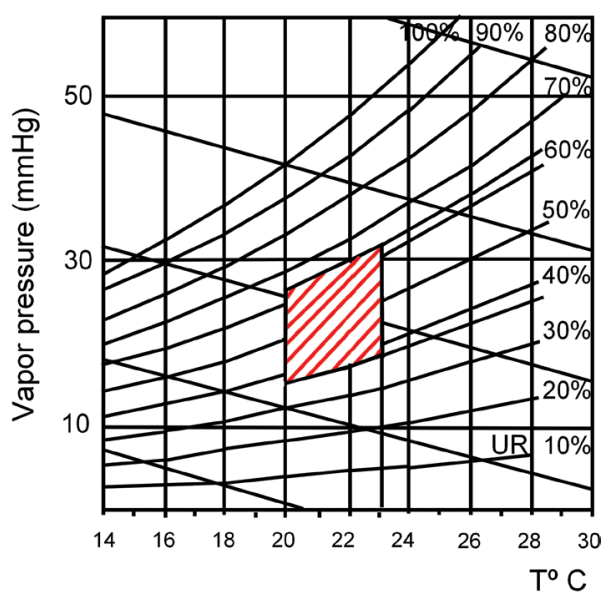

The results are presented in the following order: (1) the relationship between thermal sensation and operative temperature and relative humidity; (2) charts for obtaining the preferred ranges for operative temperature and relative humidity, \pm $2 \delta$; and (3) comfort zone with the intervals obtained from operative temperature and relative humidity.

The correlation between the thermal sensation perceived by the people and the operative temperature is observed that the range of operative temperature and relative humidity studied, a higher concentration of the neutrality condition and a slight feeling of warmth of the people for an operative temperature above $22^{\circ} \mathrm{C}$ and relative humidity around 50\% (Figure 6).

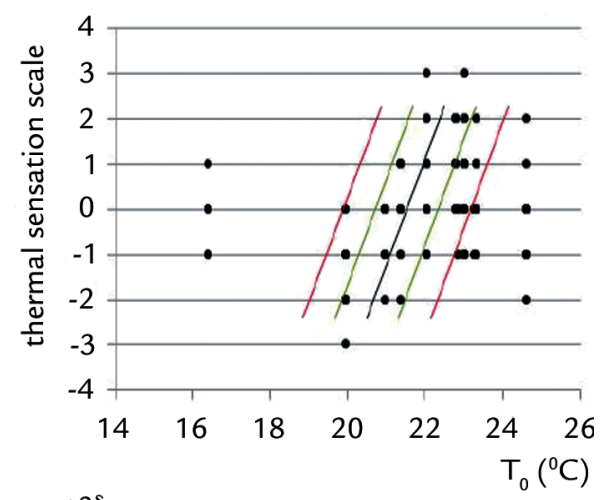

relative humidity are obtained from the intersection of the line for $-2 \delta$ and $+2 \delta$, with the line of thermal sensation of thermal neutrality (0), read this value in the " $\mathrm{x}$ " axis.

For best viewing and practice of thermal comfort, parameters used are given in the psychometric chart shown in Graph 9, plotted on the psychometric chart of Ouro Preto. 


\section{Analysis and conclusion}

Considering that the work was done in real environments where environmental and personal variables as well as the interpretation of the scale of sensations by the questioned individuals are difficult to control factors, differences can be found in the results.

In general, it is considered that around $75 \%$ of users feel comfortable when the temperature is between $20.0^{\circ} \mathrm{C}$ and $23.20 \mathrm{C}$, and relative humidity between $40 \%$ and $64 \%$. But at certain times of intense sunlight and depending on the time of the year the other building also creates some discomfort.

The collected data are particularly valuable because of the experimental conditions under which the data were collected, however, its practical application is somewhat limited, since they are valid only for particular conditions under which the experiment was performed.

Of the three buildings studied, all had problems in relation to the thermal environment. During the study two of these buildings, School of Mining and Institute of Physical and Biological Sciences, have solved part of the issues related with the installation of brise soleil, insulfim films on the windows and curtains. In the case of the Building Block of Classrooms only insulfim was placed, but this alternative has not solved the problem and therefore we developed a proposal to retrofit encompassing the installation of brise soleil mobile and increased vegetation midrange in the immediate surroundings, avoiding direct sunlight on the glass façade among other strategies.

\section{Acknowledgments}

The authors gratefully acknowledge the CAPES, CNPQ and the FAPEMIG, Brazil.

\section{References}

ALMEMO Manual for all ALMEMO measuring instruments. (4th revised edition). Germany, 2003.

AMERICAN SOCIETY FOR HEATING, REFRIGERATING AND AIR CONDITIONING ENGINEERS. ANSY/ASHRAE 55: Thermal environmental conditions for human occupancy. Atlanta, 2010. 26p.

CORGNATI, S.P., FILIPPI, M. VIAZZO, S. Perception of the thermal environment in high school and university classrooms: Subjective preferences and thermal comfort. Building and Environment, v. 42, p. 951-959, 2007.

FARIA, M. A. Avaliação das condições de conforto térmico nas salas de aula do campus morro do cruzeiro da UFOP. Ouro Preto: Escola de Minas, Universidade Federal de Ouro Preto, 2012. 157f. (Dissertação Mestrado em Engenharia Civil).

PIZARRO, P. Estudo das variáveis do conforto térmico e luminoso em ambientes escolares. Bauru, SP: Programa de Pós-graduação em Desenho Industrial, Universidade Estadual Paulista, Faculdade de Arquitetura, Artes e Comunicação, 2005. 179p. (Dissertação de Mestrado em Desenho Industrial).

RUIZ-TORRES, P., GOMES-AZPEITIA, G., BOJÓRQUEZ, G., ALCÁNTARA, A. Zona de confort com el uso de um índice térmico y humedad relativa em clima cálido subhúmedo. In: X ENCONTRO NACIONAL E VI ENCONTRO LATINO AMERICANO DE CONFORTO NO AMBIENTE CONSTRUÍDO. Anais ... ENCAC 2009, Natal, 2009, p. 1672-1681.

INTERNATIONAL ORGANIZATION FOR STANDARDIZATION. ISO 7726: Ergonomics of the thermal environment - Instruments for measuring physical quantities. Genebre, 1996. 66 p.

WONG, N. H., KHOO, S. S. Thermal comfort in classrooms in the tropics. Energy and Buildings, v. 35, p. 337-351, 2002.

Received: 25 November 2015 - Accepted: 20 July 2016. 